\title{
Digital visceral: textural play and the flamboyant gesture in digital screen violence
}

Article

Accepted Version

Purse, L. (2017) Digital visceral: textural play and the flamboyant gesture in digital screen violence. Journal of Popular Film \& Television, 45 (1). pp. 16-25. ISSN 0195-6051 doi: https://doi.org/10.1080/01956051.2017.1270137 Available at https://centaur.reading.ac.uk/67557/

It is advisable to refer to the publisher's version if you intend to cite from the work. See Guidance on citing.

Published version at: http://dx.doi.org/10.1080/01956051.2017.1270137

To link to this article DOI: http://dx.doi.org/10.1080/01956051.2017.1270137

Publisher: Taylor \& Francis

All outputs in CentAUR are protected by Intellectual Property Rights law, including copyright law. Copyright and IPR is retained by the creators or other copyright holders. Terms and conditions for use of this material are defined in the End User Agreement.

www.reading.ac.uk/centaur 
Central Archive at the University of Reading

Reading's research outputs online 


\section{Digital Visceral: Textural Play and the Flamboyant Gesture in Digital Screen Violence}

\section{Lisa Purse 2017}

Early on in 300: Rise of an Empire (Dir. Noam Murro, 2014) Athenian general Themistocles (Sullivan Stapleton) leads an attack on the Persians who have just landed at Marathon. In a sequence which shows him giving them "a taste of Athenian shock combat" as the voice over narration puts it, Themistocles runs forward, stabbing, gutting, dismembering and beheading assailants with his sword. The sequence "speed ramps" between normal speed and different slow motion speeds, with each deadly slice of the sword picked out in extreme slow motion, blood billowing out from the wound and hanging there, sometimes even being pulled into an arc by the sword's own route through the air. The blood behaves more as if it were underwater than as if it were subject to the forces of real world physics, and as my use of the term "billowing" above implies, this blood seems to be more viscous and less subject to gravity than normal blood, lending it a shape and surface texture reminiscent of clay or putty. This "blood" hangs in front of the sliced human body, a metonym for the wound it hides rather than a revelation of the wound itself, an abstraction of arterial spray rather than its faithful depiction. It floats separate from the body from which it theoretically issued, but also registers (due to its unusual, non-blood-like visual textures) as discontinuous from the generally photorealistic fleshy contours and movements of the human bodies with which it nominally shares the frame. Not just blood floating free from a body, then, but a graphic element that seems to float free of the composite in which it appears. Through this graphic element and its tracing of each sword swing, the sequence marks out the shape of Themistocles' heroism, his swordsmanship and relentless forward momentum. 
In its overt stylisation and ostentatious design, this sequence is representative of a contemporary tendency in the digitally assisted representation of violence in genre filmmaking, but it is also shaped by a longstanding cinematic tradition of depicting violence that Stephen Prince has dated from the abolition of the Production Code in 1968 ("True Lies"). Post-1968, Prince argues, the depiction of violent acts received much more "stylistically elaborate treatment," so that editing, composition, special effects and slow motion were deployed to make film violence "more insistent and expansive," a mode that continues up to the present day ("Beholding" 20). The 300: Rise of an Empire sequence and its ilk are the latest iteration of this trend, yet simply to frame contemporary film violence in this way risks flattening its stylistic specificity, which is identifiable not just by its baroque styling, but by its curious reticence either to provide a seamlessly photorealistic image, or to convince the spectator of the spatio-temporal continuity of its scenes of mayhem. This essay will examine the specificities of contemporary digital film violence in genre cinema, and explores how its logic of extreme aestheticisation relates to histories of screen violence, cinema and special effects, and to the contexts of digital media proliferation and production in which it has emerged.

It was Arthur Penn's Bonnie and Clyde (1967) and Sam Peckinpah's The Wild Bunch (1969) that heralded a step-change in the depiction of screen violence at the end of the 1960s. The qualitative difference wasn't in what was shown — what Prince calls its "referential component" — but in its "stylistic amplitude," a combination of "graphicness and duration" produced by choices made in various aspects of cinematic technique, such as performance, composition, editing, and shot length and shot speed (Classical Film Violence 35). In the two films' shoot-out scenes, the performers' reactions to bullet impacts were matched by special effects that underscored the physiological effects of bullet wounds in more textural detail 
than had been seen before. Blood-filled gelatine capsules fired at the body, and blood "squibs" attached to the body that detonated a small charge, simulated bullet impacts, with Peckinpah specifying that squibs should be positioned to depict both entry and exit wounds; later films would use squibs containing viscera as well as blood to the same ends (Cook 131). The resulting blood spurts conveyed the physiological effects of high speed bullet impacts in more precise detail than had been seen before, and lent a formal shape and a spatial expansiveness to the exiting fluid. The bodily consequences of violence were conveyed through an intensified focus on the visual textures (surface appearance, viscosity, movement) of gore. This was enabled further by the visual composition of the sequences: both directors were heavily influenced by Akira Kurosawa's practice of shooting scenes of bloody violence with multiple cameras running at different speeds to enable the intercutting of slow motion shots into montage sequences in films like Seven Samurai (1954), The Hidden Fortress (1958), Yojimbo (1961) and Sanjuro (1962) (see Cook 143-6, Prince “Aesthetic of Slow-Motion" 175-204). The resulting "temporal elasticity" (Cook 146) focussed attention on the processual shape of blood spurts and body recoils (trajectory, reach, the phrasing of movement), producing the impression of a highly choreographed display of violence, and prompting analogies to ballet from filmmakers and scholars alike. ${ }^{1}$

Here then, are the two key components of the "baroque bloodletting" that has persisted ever since ("Beholding" 11); an intensified focus on the visual textures of violence, and, as a result, an intensified focus on the shape of fictional violent injury and death and its spatial and temporal expansiveness: on, that is, its flamboyant gesture. This intensified stylistic amplitude was intended, by Peckinpah at least, to interrupt the domestication of real world violence that he felt television had achieved by "sandwiching" the Vietnam War in between commercials and thus insinuating it "into the daily routines of consumer life" 
(“Aesthetic of Slow-Motion" 175-6). The relationship of screen violence to its socio-cultural environment and to real world violence has always been at issue in this way, although these days it is much less likely that overt stylisation would be associated with waking audiences up to the realities of violence in the way Peckinpah wanted. As the history of the regulation and censorship of screen violence attests, the aesthetics and ethics of screen violence are intimately connected, but Peckinpah's approach — stylisation to remind spectators of the importance of acknowledging the consequences of real world violence — is also a useful reminder that binaries between realism on the one hand and heightened stylisation on the other are to be avoided. Instead, the textual detail of aesthetic choices, alongside their historicisation in relation to histories of screen violence, film style and special effects practices, provide crucial tools in any attempt to locate particular trends in screen violence.

In the shorter history of digital screen violence, the early years of computer-generated images' preponderance in cinema (from the late 1990s onwards) saw the deployment of CGI to achieve the cost-effective depiction of credible bloody violence. Here verisimilitude was prioritised, and digital imaging built on what had been achieved in-camera. Much discussed examples include Saving Private Ryan (Dir. Steven Spielberg, 1998) and The Passion of the Christ (Dir. Mel Gibson, 2004). In the Omaha Beach sequence near the start of Saving Private Ryan for example, 17,000 on-set squibs, amputee actors with squib-mounted prosthetic limbs, dummies and practical effects explosions were supplemented by digitally inserted wounds, blood spray, and bullet impacts on parts of the set that were too close to the actors (Magid 3). In the flagellation scene in The Passion of the Christ, the flails of the whips soldiers wield at Christ were digitally inserted, and a mixture of prosthetic make-up effects and digitally inserted skin coverings and wounds was used to depict the horrific injuries being 
inflicted by the whips' sharp, tearing teeth (Duncan 28-31; see also Prince "Beholding" 158).

Prestige productions, both films reached for an aesthetic that could convey the brutal realities of the situations they were concerned with. In each film a combination of practical, profilmic effects and digital visual effects were used to provide an accumulation over duration of roughly physiologically accurate graphic detail of gore (Roger Ebert noted that Saving Private Ryan was as graphic as any war footage he'd seen ("Saving")), accompanied by cries and ragged breaths of discomfort to underscore that these are real bodies whose suffering is of moral significance. In accordance with this emphasis, both films use slow motion to underscore not the reach, trajectory or shape of viscera or gore, but moments of intense psychological response to the scale of the suffering being experienced. The resulting "blood spurts, prosthetic wounds, and slow-motion inserts" place the violence "in a cinematic vernacular that is immediately familiar and accessible to modern viewers" (Prince "Beholding" 19), but also attempt to situate it within an emotional and moral framework which evokes "tears in the face of mortality... [and] the fragility of flesh," to paraphrase Vivian Sobchack (120). As a consequence, these scenes of violence retain a strong sense of photorealistic spatio-temporal continuity, using the contemporaneously commonplace convention of handheld camerawork to enhance the impression of "documentary realism." The graphic detail is presented as if photographed, and the presence of digital image elements is neither pointed up, nor intended to disturb or interrupt the cohesion of the image or the depicted moment. In this way such films conform to the dominant aesthetic in late 1990s and early 2000s digital compositing, which was to hide the composite nature of the image (Rodowick 158; 184-5). 
While seamlessly photorealistic digital composites of violence continue to be produced, more recently a counter movement has emerged, in which scenes of violence push stylistic amplitude in ways that move beyond the photoreal, and beyond a cohesive image. In these films, the flamboyant gesture - the expansive shape and movement — of body damage is foregrounded and temporally and/or texturally extended to the extent that textures and movements begin to register differently, and spatio-temporal continuity starts to fragment. The example from 300: Rise of an Empire that began this essay is a case in point: the filmmakers' interest in foregrounding the sanguinary swoop of the sword — the gesture — by tracking it in slow motion results in a rendering of blood that is differently textured than either commonplace ideas of what blood should looks like, or commonplace iterations of fake blood viscosities in cinema (which don't usually look putty- or clay-like in texture). Indeed, the visual and motile textures of this blood situate it explicitly as a rendering, its digital nature revealed in its ontological incongruity both with what is expected (from real blood or movie blood) and with what else is on the screen and allegedly sharing the same diegetic space (bodies that look real and move relatively realistically). One could argue that this textural unevenness in the film is the result of poor visual effects practice, perhaps as a result of financial constraints, but that would be to disregard 300: Rise of an Empire's estimated \$150 million USD budget. ${ }^{2}$ More importantly, such an assertion ignores the fact that this kind of textural "dissonance" between different elements of the image is now widespread in the violent sequences of contemporary genre cinema.

A multiplying roster of films share a similar approach to the depiction of violence seen in the moment from 300: Rise of an Empire, from 300 (Dir. Zack Snyder, 2006) and Sin City (Dir. Frank Miller and Robert Rodriguez, 2005) to Wanted (Dir. Timur Bekmambetov, 2008) and Dredd (Dir. Pete Travis, 2012), and from the Resident Evil franchise (Dir. Paul W. 
S. Anderson, 2002 - ) $)^{3}$ to the Machete films (Dir. Robert Rodriguez, 2010, 2013).

Significantly, all of these films share a citational relationship to past "low cultural" forms such as exploitation cinema or pulp fiction, or to the graphic novels and video games inspired by them. While exploitation cinema has always been an amorphous, shifting category, taking in cycles of films that have distinct artistic, production and censorship contexts from across film history (see Schaefer 2), what is common to most of branches of exploitation cinema is an aesthetic that is visually marked in some way by the low budget, time pressured circumstances of their production, and a "sensibility that emphasises sensationalism, spectacle and direct appeals to the viewer's body" (Church 10). Some of the films listed above are part of a group of explicit homages to the aesthetics, subject matter and marketing paratexts of 1960s to 1980s exploitation cinema that David Church has called 'retrosploitation' (22), including Pervert! (Dir. Jonathan Yudis, 2005), Black Snake Moan (Dir. Craig Brewer, 2006), The House of the Devil (Dir. Ti West, 2009), Black Dynamite (Dir. Scott Sanders, 2009), Hobo With a Shotgun (Dir. Jason Eisener, 2011), The Sleeper (Dir. Justin Russell, 2012), and perhaps most famously Grindhouse (2007), the Robert Rodriguez / Quentin Tarantino double bill (complete with fake trailers that eventually became features in their own right).

Regardless of whether they are retrosploitation or not, these contemporary genre films all offer spectacular deaths that are persistently visceral — focused on the violent penetration or expulsion of viscera, and its visual features and material consequences - and that are expansively flamboyant in either spatial or temporal terms, or both. Deaths and injuries are bloody, numerous, and often anatomically detailed, and depicted at variable speeds and variable shot distances that intensify the contemplation of form and texture. For example, early on in Machete Kills the title character (Danny Trejo) proves the utility of the weapon 
after which he has been named. Having hacked the heads off two attackers, Machete slices another opponent fully in half, apparently so cleanly that the two halves of the body stay together for a second before exploding apart in a flurry of blood. The rest of the film showcases equally gory and hyperbolic renderings of death and dismemberment (and stabbing, beheading, disembowelling, electrocution, and crushing) more fitting for a splatter movie like Maniac (Dir. William Lustig, 1980) than the bullet-filled vigilante revenge films such as Death Wish (Dir. Michael Winner, 1974) that are its direct antecedents. Thus we can say more than simply that the contemporary genre films in question display violence with an exploitation aesthetic — marked by inconsistencies flowing from constrained finances, and emphasising the body. It is possible to be more specific, by noting that the delineation in both the referential component and the stylistic amplitude in such scenes is drawn from an area of exploitation cinema with a very particular emphasis: that is, the "intensive focus on the body's very materiality ... through an aesthetic informed by fragmentation and violence (both physical and semiotic)" common to mondo and giallo movies, slashers, and splatter films (McRoy 197).

One could theorise that this preoccupation with the visceral is a compensation for the alleged sterility of the digital image. André Gaudreault and Philippe Marion remind us that the digital "carries with it a connotative network that attributes to it an aseptic coldness" that is frequently understood as a "void, the absence of life" and history: "[s]crubbed, hygienic, disinfected images" (75). A surfeit of flamboyantly rendered and highly textured viscerality might just compensate for what the authors memorably call the "mortiferous asepticizing" of the film image, or the fear of the same, in the digital era (76). This would connect retrosploitation and the other films' particular brand of intensified stylistic amplitude, inspired by exploitation movies past, to a larger nostalgic "turn" in contemporary cinema that 
has been prompted by the arrival of digital media culture and the lost hegemonies of celluloid and the cinema screen it has precipitated (11; see also Gilbert). Jason Sperb observes an "[a]nalog nostalgia across all aspects of popular culture - more as stylistic practice than as a substantial call back to historical periods or their modes of production - [which] attempts to deny the profoundly immaterial realities of the digital age" (16). Films like Hugo (Dir. Martin Scorsese, 2011), The Artist (Dir. Michel Hazanavicius, 2011), Super 8 (Dir. J. J. Abrams, 2011), and Oz, the Great and Powerful (Dir. Sam Raimi, 2013) encourage a nostalgic look back to earlier periods of film production, and earlier films. They do so by using digital imaging to bring the spectator into close proximity with the haptic textures of earlier cinematic and associated technologies, such as the metallic mechanics of projectors, clockwork and trains in Hugo, or the cut-out, hand-drawn layers of the "paper theatre" in the $O z$ title sequence. This type of approach seeks to reinvest the digital image with the haptic density of a "lost" materiality and the human experiences it implies; the insistent focus on the body's bloody interior, via a digital simulation of past special effects practices, might seek to do the same for contemporary film violence.

Certainly the recent films under discussion insistently hark back to the visual textures of their sources in their articulation of graphic violence, a potentially nostalgic backwards gaze at the materiality of the older special effects practices that made slashers, horrors and splatter films possible; the remembered textures of low budget special effects practices from the pre-digital era. The Machete Kills moment described earlier provides a good example, in that it is clearly designed to evoke the materiality of effects-shop-constructed foam latex body parts and prosthetics, fake blood and viscera, and the occasionally inconsistent physics of bodily movement as different practical, mechanical, creature or make-up effects interacted with each other in films like Rabid (Dir. David Cronenberg, 1977), The Thing (Dir. John 
Carpenter, 1981) and The Evil Dead (Dir. Sam Raimi, 1981) among others. This has a corresponding impact on the verisimilitude of the action, and its visual textures. The motion of the body Machete has cleaved into two has a rubber-like bounce that reduces the impression that real skin and bone have been breached. One might presume that the stickiness of real viscera might cause the two halves of the body to peel away from each other gradually at first, but instead they pull apart suddenly and arbitrarily, the catalyst (whether practical effects wires operated from off screen or digital animation) remaining unseen. The resulting blood looks like it is being splashed forwards out of a cluster of invisible buckets, rather than spurting laterally from causally legible points at which the unfortunate man's arteries and veins have been sliced.

It would be easy to read these textural and textual inconsistencies only in relation to the inconsistencies visible in the special effects work in some exploitation fare. Special effects practitioners of the 1970s and 1980s, for example, could draw on a sophisticated range of modelling, puppetry, animatronics, mechanics, creature and make-up effects to create vivid spectacles of gore and corporeal destruction. Their task was to point spectators away from the artifice of their elaborate constructions by finding ways to confer "perceptual realism" onto the body or event being filmed - that is, the sense that if it were alive, it would look like this — despite its fantastical nature. ${ }^{4}$ Movement turned out to be key to this endeavour. In The Thing, for example, when the body-snatching alien that is terrorising an arctic research base tries to escape inside the head of its human host, it rips the head free from the host body and then sprouts legs for its getaway. A phalanx of radio- and push-rodcontrols generated eye movements and changes in facial expression in the disembodied head; special make-up effects creator-designer Rob Bottin pointed out that the resulting twitches, breaths and blinks were crucial in making the alien-possessed head "look alive" (cited in 
Hogan 68). Sometimes, however, it worked less well, a not-quite-achieved special effect, or the jostle of vivid liquids and materials it involved, generating an ontological inconsistency that risked breaking the illusion. The inconsistencies described in the Machete Kills sequence above could, then, be interpreted as a kind of nostalgic textural homage to these special effects failures, but such a reading would fail to account fully for the sequence's aesthetic qualities.

If movement added to graphic detail lent perceptual realism to creature effects in The Thing, then the same combination in the Machete Kills example seems to have the opposite effect. The competing movements of body and blood spray, and the arbitrary timing and causal uncertainty of the body's collapse outwards, are displayed quite obviously: here, artifice is not pointed away from, but pointed towards. As a result, the impression of spatiotemporal continuity is undermined, and the contrasting ontologies of digital and profilmic elements are highlighted. In this way the presence of the digital, and the specificity of digital materiality, begin to come to the fore. A similar foregrounding of contrasting ontologies is evident in the horror video game-to-film franchise Resident Evil. Towards the end of Resident Evil: Afterlife (2010) heroine Alice (Milla Jovovich) must fend off two mutated canine zombies as she tries to rescue her friends Claire Redfield (Ali Larter) and Chris Redfield (Wentworth Miller) from the corporation that first unleashed the zombie-creating T-virus into the world. Alice sidesteps as the first undead dog leaps into the foreground of the shot, the creature's monstrous bifurcated head and neck, sprouting a cluster of teeth dotted around an indeterminately fleshy, growling maw, picked out in digital visceral close-up. The second dog now makes its leap, and in response Alice readies a sawn-off shotgun full of dimes (a reference to an old Western myth), shooting the dog in mid-air, generating an explosion of blood, viscera, and flat, round coins. Some of the dimes shatter two sheets of glass hanging 
from the ceiling above, and Alice raises her arms to shield herself as coins and glass shards rain down. When the first dog begins another run at Alice, she kicks a giant shard of glass, shifting its trajectory towards the canine so that the glass fatally lodges in the insides of the monster, bringing it falling to the floor with a yelp and a final burst of arterial spray.

The sequence is presented with variable speeds within and across shots: the Alice vs. mutant dogs action is unfolding at the same time as Claire and Chris are being imprisoned into storage tubes that are gradually disappearing from view; Claire and Chris are shown struggling and shouting at a normal frame rate, while the movements of Alice and the dogs play out at different slow motion speeds. Slow motion offers up the shape of movement and the textural detail of the dogs' bloody, fleshy maws to contemplation, and shifts to a quicker frame rate emphasise the force of the final kick and the final impact as the glass shard penetrates the undead canine. While the glistening open maw captured in slow motion closeup provides some of the highly textured gore we would expect, other elements of these images seem to pull apart from each other. The visual texture of the blood on the dog's body fails to respond to surface movements and corresponding changes to how light would be reflected by those surfaces; and the shattered pane of glass neither visually registers as a piece of real world glass sharing the same space as Jovovich, nor does it display the correct perceptual correspondences in terms of its weight, momentum and trajectory. Such elements appear to exist in tension with other more photorealistically elaborated elements, such as the dog's open interior, replete with glistening fleshy innards, pale sinews and carefully shaded teeth, or the profilmic presence of Alice herself. There is also a textural dissonance between the haptic force of the viscera on show and the smooth, abstracted geometry of the glass simulacra, a dissonance between flat planes and rounded objects that gestures explicitly to the digital composite's foundation in the combination of 2D and 3D computer-generated objects, 
and which is further emblematised by the spinning coins, which in their own perpendicular turning echo this tension between flat and round, 2D and 3D.

Back in 2007 David Rodowick noted that the pressure to produce visually credible digital composites constructed a normative aesthetic of digital compositing that disavowed the "intrinsic separability of image components" and stressed "smoothness, continuity, and seamless boundaries between combined elements" (158). It seems, now, that we are occupying an entirely different era of digital imaging practice. Like the other examples discussed in this essay, the Resident Evil: Afterlife sequence is unapologetically nonnaturalistic in its style of digital compositing, selecting and juxtaposing visual and motile textures that are incompatible, and foregrounding these incompatibilities in the flamboyant gesture of spatially or temporally expansive violence. In Resident Evil: Afterlife, as in Machete Kills and 300: Rise of an Empire, there is a reflexive play on the distinction between two-dimensional and three-dimensional image artefacts, between in-camera and computergenerated artifice, between blood and viscera as palpably lived materialities, profilmicallysimulated conjoinings of latex, corn syrup and food colouring (et al), and "blood" and "viscera" as digital materialities, all caught in a flamboyant gesture of death or dismemberment. This is, then, a type of "ontological montage," the "coexistence of ontologically incompatible elements within the same time and space" which Lev Manovich had, in 2002, only found on the margins of moving image culture in experimental digital art (159). Ontological montage produces a playful fragmentation of the digital composite, a knowing failure to complete the impression of spatio-temporal unity that has historically been taken for granted as a foundational aim of mainstream narrative cinema. 
One of the contexts for this is the increasing digital literacy of audiences, whose quotidian immersion in a digitally mediated environment of competing digital textures, scales and frames is matched by increasing levels of knowledge about how digital composites are constructed, courtesy of off-the-shelf versions of industry digital visual effects software like Maya and Adobe After Effects, and of making-of documentaries and visual effects practitioners' show reels that reveal the different "layers" and components that make up the composite image, and domestic or mobile digital video editing apps. Such developments have created spectators who are 'connoisseurs of compositing' (Cubitt) who understand the basic constructedness of digital compositing and its conventional deployment to bring together multiple image fragments and layers into an apparently unified whole. This knowledge shapes expectations and tolerances for aesthetic decisions, opening up the possibilities for fragmentation, for textural and compositional experimentation and play.

Ontological montage, then, becomes a contemporary feature of the intensification in stylistic amplitude that Prince first documents occurring in 1968: a playful resistance to photorealism, and to the unity of the digital composite, and a cheerful acknowledgement of the artifice of these outlandishly gory scenes of violence. Evident at the visual level, in the friction between digital and profilmic elements, this feature is often underlined by an escalation in the elaborateness and fantastical nature of the violent action across a film. To go back to Machete Kills, for example, the deaths Machete perpetrates become increasingly outlandish, speaking insistently of the presence of the digital effects necessary to bring them to the screen even as they equally insistently thematise corporeal fragmentation and destruction. In two separate instances a man is tethered to the rotating blades of a helicopter — one by his entrails, that Machete has just ripped out of him — and is pulled towards the blades, dying in a shower of blood and body parts; a group of villains on a jetty is crushed by 
a boat Machete has jack-knifed on top of them; in a later helicopter scene Machete attaches a wire tether to a helicopter that spins him round in the air, the wire slicing through an approaching mob; and near the end of the film Machete deploys an anti-matter gun that turns bodies inside out, leaving just a pile of skin and innards to slop to the floor.

This farcical escalation of different ways to suffer violent death lends the violence a comic frame that Geoff King suggests is typical of recent examples of New Hollywood violence, and which leads to both heightened affect but also a heightened awareness of artifice: the "overall effect is one of great intensity and cinematic impact but also an encouragement of awareness that this is an operatically confected, staged, and exaggerated attraction, a veritable production-number of violence" (131, original emphasis). We seem to be very close to the critique of contemporary film violence Vivian Sobchack offered back in 1999, the year that The Matrix (Dir. Wachowski siblings) used the "bullet time" variable speed digital effect to bring physical gestures under an expansively spatialised form of visual scrutiny. At that historical juncture Sobchack opined "an increasingly hyperbolic and quantified treatment of violence and bodily damage that is as much about 'more' as it is about violence," involving a "heightened reflexivity and irony [that] merely leads to a heightened sense of representation: that is, care for the film as experience and text, perhaps, but a lack of any real concern for the bodies blown away (or up) upon the screen" (121-1). King suggests this "heightening" and extreme stylisation is simply a product of the marketable "logic of upping-the-ante" he finds has applied to film violence in genre filmmaking across the New Hollywood period (128). King points out that the combination of comedy and violence can increase its affective intensity, an intensity "sought by some viewers and sold by Hollywood as part of the essence of the cinematic experience (even when transferred onto home video)" (141). 
The 'digital mutation' of which Gaudreault and Marion speak involves a digital media culture in which cinema has lost its hegemonic position (9). King's parenthetical mention of "home video" has now grown into a proliferation of moving image texts and platforms, which moves Nicholas Rombes to assert that "[a]ll films today are disposable in the sense that they end up piecemeal, fragments, in clips on the Internet" (24). But the central thrust of King's analysis stands: the affective intensity of heightened and highly stylised depictions of violence is a sought-after commodity for spectators and filmmakers, a marketable "fragment" that can serve as identifier and consumer draw. If, as Thomas Schatz has it, "violence has been a defining characteristic and signal feature of Hollywood cinema since the silent era" (1), then the extreme intensification of stylistic amplitude this essay has found in the textual detail of the films in question seeks to position contemporary genre films strongly in an expanded, multi-platform marketplace. I want to end by citing two corollary developments in the wider digital media culture, which are related to this aesthetic model for the depiction of film violence, and which imply that this attempt at marketplace positioning may well be garnering success.

The first of these developments is the way in which digitally produced television texts have taken up key aesthetic elements of contemporary genre film violence. While The Walking Dead (American Movie Classics, 2010 — ) tends towards a seamless photorealistic digital composite, for example, it takes up the flamboyant gesture and the splatter film citations in the incessant and often highly elaborate and gory killings of zombies that punctuate the series. In contrast, Spartacus (Starz Productions, 2010-2013) offers a bloodand-guts-filled imagining of Ancient Rome that acknowledges its own digital composite nature overtly, giving rise to violent sequences in which slow motion activates an 
attentiveness to a playful alternation between 2D and 3D planes, as the puncturing of bodies occasions flattened surfaces of arterial spray set against the rounded rendering of the punctured body. Ontological montage finds its most insistent and flamboyant iterations in the low budget made-for-television "mock busters" produced by The Asylum, such as the Anthony C. Ferrante-directed Sharknado (2013) and Sharknado 2: The Second One (2014). For example, towards the end of Sharknado 2, hero Fin Shepard (Ian Ziering) has been launched into the air by an explosion, and shares his fall with hundreds of sharks that have been tormenting the city following a freak weather system. Fin grabs a falling chain saw, starts it up, and launches himself straight into the mouth of a giant shark, chain-sawing his way out to kill the beast in a spray of shark viscera. The violent scenes in The Asylum productions make barely any concession to verisimilitude, photorealism, or seamlessness, producing instead a bricolage of combinant elements of monsters, objects, terrified humans, blood and gore that has minimal cohesion at the visual level, but that represents a celebration of outlandish, overtly composited, artifice.

The second development is connected to the large-scale emergence of user-producers in digital media culture, what Axel Bruns has termed "produsage" (Blogs) and Vito Campanelli calls the remixer imperative (208), which means that moving image texts must develop "salience" in order to be selected for further circulation across social media platforms and video sharing sites. In this regard, as digital entrepreneur Mark Pesce points out, the audience "will always select the production which speaks to them most directly" (105). We can see the salience of contemporary genre film violence demonstrated by the ways in which it has migrated across not just other media contexts (such as television) but also user-generated contexts. Much has been made of the fan-produced exploitation trailers made in response to the retrosploitation cycle, for example (see Church for an insightful 
account of this phenomenon), but much less has been made of so-called "kill count" videos, user-generated video mash-ups that compile and count up film deaths. For example, a video might cut together all the deaths in a film or film series, all deaths initiated by a film character or actor in one film, or across a film series or a person's filmography. Some videos even pit different characters or actors from the same movie or film series against each other. ${ }^{5}$

The videos are produced by fans of the films, sometimes curated by particular fan websites, such as All Outta Bubble Gum (“Keeping Track of On-Screen Death Since 2009”), or by individuals. The relatively recent fan practice dates from the mid-2000s, and connects to "body count" practices by websites such as Movie Body Counts (2005-2009) and Body Counters (2006-), which offer numerical body counts without video illustration. ${ }^{6}$ The onscreen numerical counter (reminiscent of a video game "heads-up display" or "HUD”) and the quick succession of "kills" borrow from the experiential logic of first-person shooter video games, and it is worth noting that many of these video games themselves offer a highly spatially and temporally extended mode of bloody death that seems to have been drawn from exploitation cinema, from the sanguinary, drawn-out chainsaw beheadings of the Gears of War franchise (Epic Games 2006 — ), to the slow motion dismemberments of Ryse: Son of Rome (Crytek, 2013). Top hits in a February 2016 YouTube search revealed kill count videos for James Bond, Luke Skywalker and Darth Vader (the latter two reflecting the recent release of Star Wars: The Force Awakens (Dir. J. J. Abrams, 2015)); action stars Arnold Schwarzenegger and Jean-Claude Van Damme; horror movies 2001 Maniacs (Dir. Tim Sullivan, 2005), the $S A W$ series (2004 - 2010) ${ }^{7}$, Stitches (Dir. Conor McMahon, 2012) and Silent Night (Dir. Steve C Miller, 2012); action movie Mad Max: Fury Road (Dir. George Miller, 2015), and exploitation movie pastiche Hobo With a Shotgun. 
As the list of films, characters and actors above shows, kill count videos offer the opportunity to appreciate, appraise and make claims for the value of the graphic textures and flamboyant gestures of a wide-ranging history of low budget action or horror movies, as well as animated movies and video game play-throughs, but contemporary violent genre films receive particular attention, with Machete and Machete Kills inspiring at least nine kill count videos alone. The YouTube video "Machete Kills (2013) Killcount Redux" by user Dmitri Krosser (2014), for example, assembles clips of each death in the film in the order in which they appear, presented to the accompaniment of a song from the film soundtrack, and a numerical intertitle that advances each time a "kill" occurs. ${ }^{8}$ By editing out the non-violent bits of these movies, such fan practices repeat and thus curate the moment of intensified stylistic amplitude present in the original violent sequence. In the process, the user-producer effectively performs their own intensification of stylistic amplitude, and indicates that it is in these violent sequences' heightened visual textures and flamboyant gestures that the pleasure and cultural capital of the films lies. ${ }^{9}$

This essay has sought to document a contemporary trend in genre film violence that intensifies stylistic amplitude to an extreme that pulls apart the normative seamlessness of the digital composite in ways that speak not only to the varied histories of screen violence, exploitation cinema, and special effects, but to the digital moment in which the trend has emerged. Directing attention towards hyperbolic iterations of spatial and temporal extension and visual texture in a flamboyant gesture of violence that remediates previous exploitation aesthetics, while signalling and celebrating its own artifice, this contemporary "digital visceral" produces an affective intensity that has permitted its success in a crowded digital media marketplace. To use Bob Rehak's useful phrase (29), this digital visceral has become a vivid "microgenre," that is migrating across digital and social media platforms, and which at 
the time of writing which doesn't show any immediate sign of reaching the end of its cultural lifespan from novelty to over-familiarity.

\section{Notes}

${ }^{1}$ Arthur Penn himself called the shoot-out at the end of Bonnie and Clyde a "ballet of death" (cited in Cook 1999: 140), and David Cook calls this mode of film violence "ballistic balletics" (130).

${ }^{2}$ Figures taken from <http://pro.boxoffice.com/statistics/movies/sequel-to-300-2013> and accessed 26 January 2016.

${ }^{3}$ Resident Evil (2002), Resident Evil: Apocalypse (2004), Resident Evil: Extinction (2007), Resident Evil: Afterlife (2010), Resident Evil: Retribution (2012), Resident Evil: The Final Chapter (2017).

${ }^{4}$ See Prince ("True Lies" 32) for a fuller discussion of his conceptualisation of "perceptual realism."

${ }^{5}$ For example, user payndz's “Die Hard Killathon!” (2008), which compiles John McClane's kills across the franchise (https://www.youtube.com/watch?v=UJaHzHwTTZs), and user Robert Bodi’s video “Machete Kills Michelle Rodriguez VS Sofia Vergara” (2014) (https://www.youtube.com/watch?v=gJUuY2RGm1o).

${ }^{6}$ See <www.allouttabubblegum.com>; <http://www.moviebodycounts.com/index.htm>; <http://www.bodycounters.com/>, accessed 1 February 2016.

${ }^{7}$ Saw (Dir. James Wan, 2004), Saw II (Dir. Darren Lynn Bousman, 2005), Saw III (Dir. Bousman, 2006), Saw IV (Dir. Bousman, 2007), Saw V (Dir. David Hackl, 2008), Saw VI (Dir. Kevin Greutert, 2009), Saw 3D: The Final Chapter (Dir. Greutert, 2010). 
${ }^{8}$ Video available at: https://www.youtube.com/watch?v=WWgDPnj0BgI [accessed 1st February 2016]

${ }_{9}^{9}$ For more on the taste indicators of aggregated YouTube fan curation, see Jenkins et al 2013: 94-5.

\section{Works Cited}

Axel Bruns. Blogs, Wikipedia, Second Life, and Beyond: From Production to Produsage. Oxford: Peter Lang, 2008.

Vito Campanelli. Web Aesthetics: How Digital Media Affect Culture and Society. Institute of Network Cultures. New York: NAi Publishers, 2010.

David Church. Grindhouse Nostalgia: Memory, Home Video and Exploitation Film Fandom. Edinburgh: Edinburgh University Press, 2015.

David Cook. "Ballistic Balletics: Styles of Violent Representation in The Wild Bunch and After.” Sam Peckinpah's The Wild Bunch. Ed. Stephen Prince. Cambridge: Cambridge University Press, 1999. 130-54.

Sean Cubitt. "The Brown Trout of Oblivion: Of Time and Special Effects.” Keynote paper,

The Magic of Special Effects Conference, Montreal, Canada, 6 November 2013, accessible at <https://vimeo.com/82097948>.

Jody Duncan. "Passion Play.” Cinefex 97 (2004). 27-40. 
Roger Ebert. "Saving Private Ryan.” RogerEbert.com. 24 July 1998. Accessed 14 December 2015 <http://www.rogerebert.com/reviews/saving-private-ryan-1998>.

André Gaudreault and Philippe Marion. The End of Cinema? A Medium in Crisis in the Digital Age. New York: Columbia University Press, 2015.

Andrew Gilbert. "The Death of Film and the Hollywood Response." Senses of Cinema 62 (April, 2012). Accessed 1 December 2015 <http://sensesofcinema.com/2012/featurearticles/the-death-of-film-and-the-hollywood-response/>.

David J. Hogan. “The making of The Thing, and Rob Bottin's eye-popping, razzle-dazzle makeup effects." Cinefantastique 13.2-3 (November/December, 1982), 48-58, 63-74.

Henry Jenkins et al. Spreadable Media: Creating Value and Meaning in a Networked Culture. New York: New York University Press, 2013.

Geoff King. “'Killingly funny': mixing modalities in New Hollywood's comedy-withviolence.” New Hollywood Violence. Ed. Steven Jay Schneider. Manchester: Manchester University Press, 2004. 126-143.

Ron Magid. "Blood on the Beach." American Cinematographer (December 1998). Accessed 14 December 2015 <https://www.theasc.com/magazine/dec98/Blood/pg1.htm>.

Lev Manovich. The Language of New Media. Cambridge, Massachusetts: MIT Press, 2002. 
Jay McRoy. “'Parts is Parts': Pornography, Splatter Films and the Politics of Corporeal

Disintegration.” Horror Zone. Ed. Ian Conrich. London: I.B. Taurus, 2010. 191-204.

Mark Pesce. "Hypercasting." LAB: A wide-angle view of visual culture 0.5 (2006). 102-7. Accessed 1 February 2016 <http://lab-zine.com/issues/0_5/articles/hypercasting/>.

Stephen Prince. “True Lies: Perceptual Realism, Digital Images, and Film Theory.” Film Quarterly 49.3 (Spring 1996). 27-37.

Stephen Prince. "The Aesthetic of Slow-Motion Violence in the Films of Sam Peckinpah.” Screening Violence. Ed. Stephen Prince. London: Athlone, 2000. 175-204.

Stephen Prince. Classical Film Violence: Designing and Regulating Brutality in Hollywood Cinema, 1930-1968. London: Rutgers University Press, 2003.

Stephen Prince. "Beholding Blood Sacrifice in The Passion of the Christ: How Real Is Movie Violence?" Film Quarterly (Summer 2006) 59.4. 11-22.

Bob Rehak. "The Migration of Forms: Bullet Time as Microgenre.” Film Criticism 32.1 (Fall 2007). 26-48.

David Rodowick. The Virtual Life of Film, London: Harvard University Press, 2007.

Nicholas Rombes. Cinema in the Digital Age, Wallflower Press, 2009. 
Eric Schaefer. “Bold! Daring! Shocking! True!” A History of Exploitation Films, 1919-1959.

Durham, NC: Duke University Press, 1999.

Thomas Schatz. "Introduction.” New Hollywood Violence. Ed. Steven Jay Schneider. Manchester: Manchester University Press, 2004. 1-10.

Vivian Sobchack. "Afterword" (1999) to "The Violent Dance: A Personal Memoir of Death in the Movies.” Screening Violence. Ed. Stephen Prince. London: Athlone, 2000. 110-124. “The Violent Dance...” originally appeared in Journal of Popular Film 3.1 (Winter 1974). 2-14.

Jason Sperb. Flickers of Film: Nostalgia in the Time of Digital Cinema. London: Rutgers University Press, 2016 